ARTICLE

\title{
Heme biosynthesis depends on previously unrecognized acquisition of iron-sulfur cofactors in human amino-levulinic acid dehydratase
}

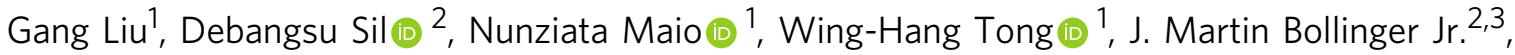 \\ Carsten Krebs (i) ${ }^{2,3 凶} \&$ Tracey Ann Rouault (iD ${ }^{1 凶}$
}

Heme biosynthesis and iron-sulfur cluster (ISC) biogenesis are two major mammalian metabolic pathways that require iron. It has long been known that these two pathways interconnect, but the previously described interactions do not fully explain why heme biosynthesis depends on intact ISC biogenesis. Herein we identify a previously unrecognized connection between these two pathways through our discovery that human aminolevulinic acid dehydratase (ALAD), which catalyzes the second step of heme biosynthesis, is an Fe-S protein. We find that several highly conserved cysteines and an Ala306-Phe307-Arg308 motif of human $A L A D$ are important for $\left[\mathrm{Fe}_{4} \mathrm{~S}_{4}\right]$ cluster acquisition and coordination. The enzymatic activity of human ALAD is greatly reduced upon loss of its Fe-S cluster, which results in reduced heme biosynthesis in human cells. As ALAD provides an early Fe-Sdependent checkpoint in the heme biosynthetic pathway, our findings help explain why heme biosynthesis depends on intact ISC biogenesis.

\footnotetext{
${ }^{1}$ Eunice Kennedy Shriver National Institute of Child Health and Human Development, National Institutes of Health, Bethesda, MD, USA. ${ }^{2}$ Department of Chemistry, The Pennsylvania State University, University Park, PA 16802, USA. ${ }^{3}$ Department of Biochemistry and Molecular Biology, The Pennsylvania State

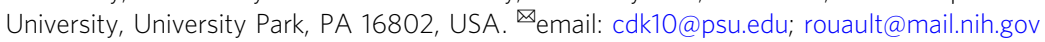


n mammalian cells, substantial amounts of iron are consumed by heme biosynthesis and iron-sulfur cluster (ISC) biogenesis ${ }^{1,2}$. Heme is synthesized by eight sequential enzymatic steps ${ }^{3}$, of which the first takes place in the mitochondrial matrix, where 5-aminolevulinate synthase (ALAS) catalyzes the condensation of succinyl-CoA with glycine to generate ALA (Supplementary Fig. 1) 3,4 . Two ALAS genes are present in vertebrates, a ubiquitously expressed ALAS1 and an erythroidspecific $A L A S 2^{2,5}$. The mRNA of ALAS2 has an iron responsive element (IRE) in its 5'-untranslated region (UTR) and is posttranscriptionally regulated by the iron regulatory proteins (IRP1 and IRP2) $)^{6,7}$. Since IRP1 loses its IRE-binding activity when it ligates an Fe-S cluster, ALAS2 protein levels are indirectly regulated by ISC biogenesis because (i) binding of apo-IRP1 to the IRE represses ALAS2 translation and (ii) holo-IRP1 (with its Fe-S cluster intact) lacks IRE-binding activity ${ }^{6,7}$. ALAS1, which catalyzes the rate-limiting step of heme biosynthesis in non-erythroid cells $^{3}$, is subject to negative feedback regulation by cellular heme content ${ }^{8,9}$. After its synthesis in mitochondria, ALA is exported to the cytosol, where ALA dehydratase (ALAD) catalyzes the second step of heme biosynthesis by condensing two ALA molecules into porphobilinogen (Supplementary Fig. 1). ALAD is evolutionarily conserved and constitutes an important enzyme for biosynthesis of chlorophyll, the corrin ring of vitamin B12, and other important tetrapyrroles ${ }^{10,11}$. After three additional enzymatic reactions in the cytosol and two in the mitochondria, the final insertion of ferrous iron into protoporphyrin IX to generate heme occurs in the mitochondrial matrix and is catalyzed by ferrochelatase (FECH) (Supplementary Fig. 1) ${ }^{4}$. Human FECH is an Fe-S protein ${ }^{12-14}$, and its stability depends on coordination of a $\left[\mathrm{Fe}_{2} \mathrm{~S}_{2}\right]$ cluster ${ }^{12,15}$, whereas the FECH of $S$. cerevisiae is not an $\mathrm{Fe}-\mathrm{S}$ protein ${ }^{12,14}$.

Iron-sulfur clusters are ancient prosthetic groups with essential biological functions ${ }^{16-19}$. In the mitochondria of mammalian cells, ISCs are assembled de novo by a complex composed of NFS1, ISD11, ACP, the ISCU scaffold and frataxin ${ }^{20}$. After assembly, nascent clusters are transferred by the HSPA9/HSC20 chaperone/cochaperone system directly to recipient proteins or through intermediate scaffolds ${ }^{21}$. Previous models have proposed that initial Fe-S synthesis occurs solely in the mitochondrial matrix $^{22}$. However, the core mammalian ISC components have also been identified in the cytosol and nucleus, and accumulating evidence shows that the ISC biogenesis machineries likely operate independently to generate nascent clusters in several subcellular compartments of multicellular eukaryotes ${ }^{23-25}$.

Thus far, there are two well-characterized nodes in the heme biosynthetic pathway of mammalian cells at which defects in the $\mathrm{Fe}-\mathrm{S}$ biogenesis machinery can suppress heme synthesis. First, FECH of higher eukaryotes contains a $\left[\mathrm{Fe}_{2} \mathrm{~S}_{2}\right]$ cluster that is proposed to stabilize the enzyme ${ }^{12,13}$. Second, ALAS2 is post-transcriptionally regulated in erythroid cells by the interconversion of IRP1 between its holo-form, which functions as cytosolic aconitase, and its IRE-binding apo form, which represses ALAS2 expression ${ }^{7}$. Therefore, Fe-S biogenesis defects can block heme synthesis by either repressing ALAS2 synthesis in erythroid cells or inactivating FECH. However, it remains unexplained how Fe-S biogenesis defects in yeast result in impaired heme production ${ }^{26,27}$, given that yeast $\mathrm{FECH}$ is not an $\mathrm{Fe}-\mathrm{S}$ protein and yeast lack IRPs ${ }^{12,14}$. The absence of an obvious explanation for the observed link between Fe-S biogenesis and heme biosynthesis in yeast drove us to search for unrecognized intersections between the $\mathrm{Fe}-\mathrm{S}$ and heme biosynthesis pathways.

We previously reported that binding of HSC20 to a leucinetyrosine-arginine (LYR) motif of succinate dehydrogenase complex subunit B (SDHB) was essential for ISC incorporation into
$\mathrm{SDHB}^{28}$. The LYR motif was also identified in other HSC20binding proteins ${ }^{28,29}$. Therefore, we speculated that analyzing protein sequences for the presence of the LYR motif and motifs with similar chemical properties (LYR-like motifs) could be used to discover candidate $\mathrm{Fe}-\mathrm{S}$ proteins ${ }^{28,30}$. Although the importance of the LYR motif for ISC acquisition was initially discovered in studies of SDHB, in which mutagenesis of LYR-like motifs in the sequences of either $\mathrm{SDHB}^{28}$ itself or in the accessory factor required for SDH assembly, known as SDHAF1 ${ }^{31}$, impaired ISC transfer to SDHB. Subsequent experiments demonstrated that LYR motifs were also important for ISC acquisition in respiratory chain complexes I and III as they were able to mediate direct binding of the cochaperone HSC20 (HSCB) that facilitated ISC transfer from the primary Fe-S biogenesis complex ${ }^{29}$. Short motifs are compact binding modules that typically regulate and coordinate protein processing, localization and degradation events ${ }^{32}$, often by engaging in low affinity transient interactions with a binding site in a protein domain ${ }^{32}$.

Our previous extensive studies defined some molecular requirements for a three-residue amino acid sequence to function as a LYR-like motif. The first position must be a small amino acid with a more aliphatic character, including leucine, isoleucine, valine and alanine. The second position must be either $\mathrm{Y}$ or $\mathrm{F}$ (aromatic), and the third position must be either $\mathrm{R}$ or $\mathrm{K}$ (positively charged $)^{28,30}$. Therefore, we used bioinformatics to screen heme biosynthetic enzymes for the presence of LYR-like motifs, as they have been experimentally shown to bind the cochaperone HSC20 to facilitate ISC transfer from the initial biogenesis complex to recipient proteins. We found that ALAD contained a LYR-like motif $\left(\mathrm{A}_{306} \mathrm{~F}_{307} \mathrm{R}_{308}\right)$. Our identification of a motif in human $\operatorname{ALAD}\left(\mathrm{A}_{306} \mathrm{~F}_{307} \mathrm{R}_{308}\right)$ that conforms to these rules, along with the presence of zinc in the crystal structure of the enzyme purified aerobically, suggested that ALAD might bind a Fe-S cluster.

Here, we show that ALAD does indeed require a $\left[\mathrm{Fe}_{4} \mathrm{~S}_{4}\right]$ cofactor for optimal enzymatic activity upon overexpression in human cells and in bacteria. We also report additional functional studies to elucidate the molecular mechanisms by which human ALAD acquires and coordinates the $\left[\mathrm{Fe}_{4} \mathrm{~S}_{4}\right]$ cluster, and to demonstrate the biological significance of the $\left[\mathrm{Fe}_{4} \mathrm{~S}_{4}\right]$ cluster.

\section{Results}

Human ALAD coordinates a $\left[\mathrm{Fe}_{4} \mathrm{~S}_{4}\right]$ cluster. At the outset, we explored whether there might be as-yet-uncharacterized intersections between the $\mathrm{Fe}-\mathrm{S}$ and heme biosynthetic pathways. We first simultaneously knocked down the mitochondrial and cytosolic ISCU isoforms, which constitute the primary Fe-S biogenesis scaffolds in mammalian cells. Overexpression of yeast FECH, a non-Fe-S enzyme, did not restore heme biosynthesis in ISCUdeficient cells (Supplementary Fig. 2a-c and Supplementary Results and Discussion). We next overexpressed a cytosolic ISCU mutant that impairs Fe-S biogenesis in the cytosol of mammalian cells and found that heme biosynthesis was inhibited (detailed in the Supplementary Results and Discussion and Supplementary Fig. 2d-f). Taken collectively, these results implied that one or more cytosolic heme biosynthetic steps were dependent on Fe-S biogenesis.

Then we screened the amino acid (AA) sequences of cytosolic heme biosynthesis enzymes for conserved LYR or LYR-like motifs that might indicate the presence of an Fe-S cluster ligated by the protein. Sequence alignment showed that human ALAD contains six cysteines, C119, C122, C124, C132, C162, and C223, and a LYR-like motif (Ala306-Phe307-Arg308) that are conserved among eukaryotic ALAD orthologs (Supplementary Fig. 3). Therefore, in terms of AA sequence and composition, ALAD 
a

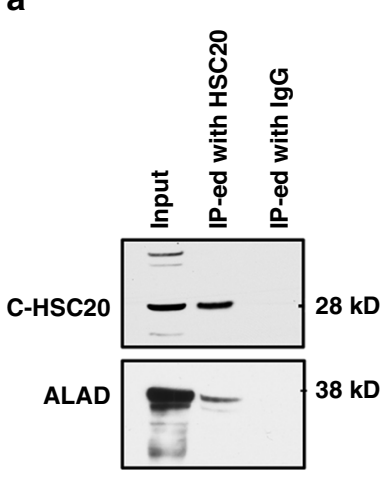

b

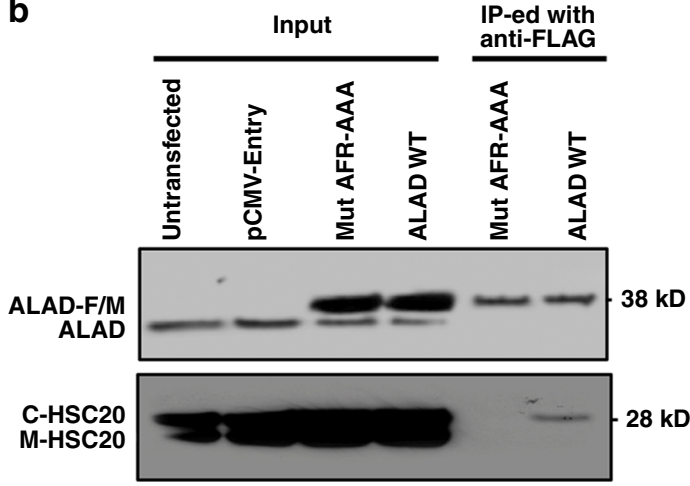

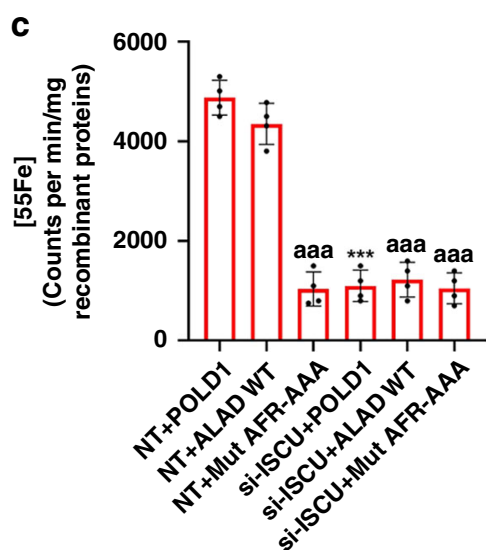

f



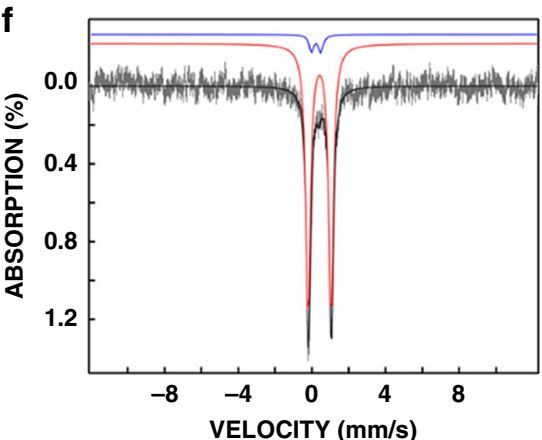

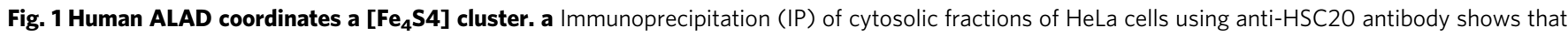
ALAD co-precipitates with HSC20. The input was $5 \%$ of the cytosolic fraction lysate, and the remaining $95 \%$ of the lysate was subjected to IP with antiHSC2O antibody. The eluates were then subjected to Western blotting with anti-HSC2O and anti-ALAD antibodies. The experiments were repeated twice independently with similar results $\mathbf{b}$ IP of whole-cell lysates of HeLa cells transfected with plasmids expressing C-terminally FLAG/MYC-tagged wild-type ALAD (ALAD WT) or the AFR to AAA mutant (Mut AFR-AAA). The inputs were $10 \%$ of lysates used in the IPs. Untransfected HeLa cells or HeLa cells transfected with empty vector ( $p C M V$-Entry) were used as controls. The experiments were repeated twice independently with similar results. These results indicated that the AFR motif of human ALAD was important for its interaction with HSC20. c 55 Fe incorporation into C-terminally FLAG/MYCtagged POLD1 (POLD1), ALAD WT and Mut AFR-AAA in HEK293 cells transfected with nontargeting siRNA (NT) or On-TARGETPlus siRNA pools against human ISCU (si-ISCU). The data are presented as mean values \pm standard deviations of $n=4$ biologically independent samples. Two-sided unpaired

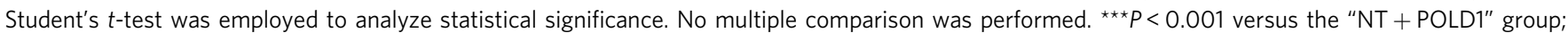
aaa $P<0.001$ versus the "NT + ALAD WT" group. The exact $P$ values are provided in the Source Data file. d UV-vis spectra of C-terminally FLAG/MYCtagged ALAD WT (orange line) and Mut AFR-AAA (yellow line) that were expressed in Expi293 cells and purified anaerobically. e UV-vis spectrum of the MBP-ALAD purified anaerobically from E. coli showing absorbance at $420 \mathrm{~nm}$. $\mathbf{f}$ Experimental $4.2-\mathrm{K} / 53-\mathrm{mT}$ Mössbauer spectrum of the MBP-ALAD purified anaerobically from $E$. coli (black vertical bars) and simulation (black solid line) along with contributions from individual subspectra associated with $\left[\mathrm{Fe}_{4} \mathrm{~S}_{4}\right]^{2+}$ (red line) and $\left[\mathrm{Fe}_{2} \mathrm{~S}_{2}\right]^{2+}$ clusters (blue line) with parameters quoted in the text.

appeared to be a candidate $\mathrm{Fe}-\mathrm{S}$ protein that might link ISC biogenesis and heme biosynthesis.

As we have previously shown that de novo Fe-S biosynthesis occurs in parallel in the mitochondrial and cytosolic compartments of mammalian cells ${ }^{23}$, we first determined whether human ALAD interacted with cytosolic HSC20. When the cytosolic fraction of HeLa cells was immunoprecipitated with anti-HSC20 antibody, the eluate contained ALAD (Fig. 1a), suggesting that endogenous cytosolic HSC20 (C-HSC20) interacted with ALAD. Because HSC20 binds directly to LYR motifs, permitting transfer of nascent clusters from ISCU to recipient proteins ${ }^{16,28}$, we then determined whether the AFR motif of human ALAD was important for its interaction with HSC20. We transfected HeLa cells with plasmids expressing FLAG/MYC-tagged wild-type ALAD (ALAD WT) or the ALAD AFR to alanine mutant (Mut AFR-AAA). Lysates from these cells were immunoprecipitated with anti-FLAG antibody, and the eluates were analyzed by western blotting. As shown in Fig. 1b, wild-type ALAD interacted specifically with C-HSC20 but not with the lower-molecularweight mitochondrial HSC20 (M-HSC20), as expected, given that ALAD is a cytosolic enzyme. No interaction between C-HSC20 and the AFR-AAA mutant was detected. Collectively, these data demonstrated that ALAD interacted with C-HSC20 and that the AFR motif of ALAD was important for the interaction.

To investigate whether human ALAD coordinates an ISC in human cells, we quantified ${ }^{55} \mathrm{Fe}$ incorporation into C-terminally FLAG/MYC-tagged ALAD WT, C-terminally FLAG/MYCtagged Mut AFR-AAA and C-terminally FLAG/MYC-tagged POLD1 (a protein known to acquire its $\left[\mathrm{Fe}_{4} \mathrm{~S}_{4}\right]$ cluster in the cytosol $^{33}$ ) in HEK293 cells transfected with either a pool of nontargeting siRNAs (NT) or with siRNAs directed against human ISCU (si-ISCU). We found that ALAD and POLD1 bound comparable amounts of ${ }^{55} \mathrm{Fe}$ in control HEK293 cells transfected with nontargeting siRNAs (Fig. 1c and Supplementary Fig. 4a). Mut AFR-AAA, which did not interact with C-HSC20 (Fig. 1b), bound significantly less ${ }^{55} \mathrm{Fe}$ than ALAD WT in NT HEK293 cells (Fig. 1c, $P<0.001$ ). Compared with control cells, ALAD and POLD1 bound significantly less ${ }^{55} \mathrm{Fe}$ in HEK 293 cells with their ISC assembly machinery rendered defective by silencing of human ISCU (Fig. 1c and Supplementary Fig. 4a, $P<0.001)$. Taken together, these results demonstrated that ALAD bound iron, presumably in the form of an ISC, in human cells. To 
determine whether human ALAD coordinated an ISC in human cells, we overexpressed C-terminally FLAG/MYC-tagged ALAD WT and Mut AFR-AAA in Expi293 cells and purified the recombinant proteins anoxically. Anaerobically purified recombinant ALAD migrated as a single band on SDS-PAGE (Supplementary Fig. 4b) and exhibited a shoulder at $\sim 420 \mathrm{~nm}$ in its UV-vis absorption spectrum (Fig. 1d), suggesting the presence of $\left[\mathrm{Fe}_{4} \mathrm{~S}_{4}\right]$ cluster(s) ${ }^{34-36}$.

We next expressed N-terminally MBP-tagged human ALAD (MBP-ALAD) in growing bacteria along with the $A$. vinelandii isc operon, which encodes the basic Fe-S biogenesis proteins and can assist iron-sulfur cluster assembly in bacteria, and purified the expressed protein anoxically 37,38 . The anaerobically purified MBPALAD was brown (Supplementary Fig. 4c), migrated as a single band on SDS-PAGE (Supplementary Fig. 4d), and also exhibited a shoulder at $\sim 420 \mathrm{~nm}$ in its UV-vis absorption spectrum (Fig. 1e).

To validate the presence of (an) $\left[\mathrm{Fe}_{4} \mathrm{~S}_{4}\right]$ cluster(s) and determine cluster stoichiometry, a ${ }^{57} \mathrm{Fe}$-enriched MBP-ALAD sample was analyzed by Mössbauer and EPR spectroscopies. The 4.2-K Mössbauer spectrum collected in a $53 \mathrm{mT}$ magnetic field applied parallel to the direction of $\gamma$ radiation (Fig. 1f, black vertical bars) was dominated by a quadrupole doublet with parameters typical of $\left[\mathrm{Fe}_{4} \mathrm{~S}_{4}\right]^{2+}$ clusters [isomer shift $(\delta)$ of $0.44 \mathrm{~mm} / \mathrm{s}$ and quadrupole splitting parameter $\left(\Delta E_{Q}\right)$ of $1.24 \mathrm{~mm} / \mathrm{s}, 95 \%$ of total intensity, red line $]^{17,39}$. In addition, the spectrum revealed a second minor quadrupole doublet with parameters typical of an $\left[\mathrm{Fe}_{2} \mathrm{~S}_{2}\right]^{2+}$ cluster $\left(\delta=0.28 \mathrm{~mm} / \mathrm{s}\right.$ and $\Delta E_{Q}=0.50 \mathrm{~mm} / \mathrm{s}, 5 \%$ of total intensity, blue line). As wild-type ALAD binds $3.5 \mathrm{Fe}$ per protein monomer (vide infra), the Mössbauer results implied that each ALAD monomer contained $\sim 0.8\left[\mathrm{Fe}_{4} \mathrm{~S}_{4}\right]^{2+}$ and $\sim 0.1\left[\mathrm{Fe}_{2} \mathrm{~S}_{2}\right]^{2+}$. $\left[\mathrm{Fe}_{2} \mathrm{~S}_{2}\right]^{2+}$ clusters are known to form by degradation of $\left[\mathrm{Fe}_{4} \mathrm{~S}_{4}\right]^{2+}$ clusters ${ }^{37}$. Therefore, the small fraction of $\left[\mathrm{Fe}_{2} \mathrm{~S}_{2}\right]^{2+}$ cluster associated with the minor doublet could have arisen by breakdown of a fraction of the $\left[\mathrm{Fe}_{4} \mathrm{~S}_{4}\right]^{2+}$ clusters. Consistent with the Mössbauer analysis, the EPR spectrum of as-purified MBP-ALAD showed no signal (Supplementary Fig. 5a), while that of the dithionite-reduced MBP-ALAD showed weak signals corresponding to $\left[\mathrm{Fe}_{4} \mathrm{~S}_{4}\right]^{+}$cluster resulting from the reduction of the $\left[\mathrm{Fe}_{4} \mathrm{~S}_{4}\right]^{2+}$ cluster (Supplementary Fig. 5b). Taken together, these results demonstrated that human ALAD harbored one $\left[\mathrm{Fe}_{4} \mathrm{~S}_{4}\right]$ cluster per monomer when it was expressed in E. coli along with the isc operon and purified anaerobically.

It is known for other enzymes that employ $\left[\mathrm{Fe}_{4} \mathrm{~S}_{4}\right]$ cofactors to promote dehydration reactions (e.g., dihydroxyacid dehydratase, aconitase, quinolinate synthase) that the substrate is coordinated by the unique Fe site of the cluster that lacks a cysteine ligand from the protein ${ }^{40,41}$. Substrate coordination by the three-coordinate iron of the cluster can perturb the Mössbauer spectra of the $\left[\mathrm{Fe}_{4} \mathrm{~S}_{4}\right]^{2+}$ cofactors and EPR spectra of the $\left[\mathrm{Fe}_{4} \mathrm{~S}_{4}\right]^{+}$forms ${ }^{42}$. We therefore tested whether binding of the substrate, ALA, or of the potent ALAD inhibitor, succinylacetone $(\mathrm{SA})^{43}$, to the $\left[\mathrm{Fe}_{4} \mathrm{~S}_{4}\right]$-containing recombinant $\mathrm{ALAD}$ perturbs the spectroscopic features of the cofactor. Addition of either the substrate or the inhibitor did not cause a detectable perturbation to either the Mössbauer spectrum of the oxidized form of the cluster or the EPR spectrum of the dithionite-reduced protein (Supplementary Fig. 6). These observations suggested either that the substrate/inhibitor/product did not coordinate the cluster or that their coordination did not perturb the spectra. Alternatively, the octameric nature of the protein and fraction-of-sites behavior ${ }^{44}$ could result in a lower fraction of substrate/inhibitor-bound form, making any perturbation more difficult to detect.

The $\left[\mathrm{Fe}_{4} \mathrm{~S}_{4}\right]$ cluster is important for ALAD activity in vitro. ALAD was previously identified as a zinc enzyme, and structures with zinc in the active site have been studied ${ }^{45,46}$. Therefore, to determine whether the $\left[\mathrm{Fe}_{4} \mathrm{~S}_{4}\right]$ cluster detected in human ALAD is functionally significant, we compared the enzymatic activities of aerobically purified wild-type apo-ALAD (aero-apo-ALAD WT, see the Methods section for details), aerobically purified wild-type ALAD (aero-ALAD WT, aerobically purified wild-type ALAD prior to treating with EDTA), aerobically purified wild-type zinc-boundALAD (aero-Zn-ALAD WT), and the anaerobically purified wildtype ALAD. As demonstrated by the ICP-MS analysis, aero-apoALAD WT did not contain iron or zinc, while aero-ALAD WT contained no zinc and a small amount of iron (Fig. 2a). The enzymatic activity of aero-Zn-ALAD WT was approximately six times higher than aero-apo-ALAD WT and two times higher than aero-ALAD WT (Fig. 2a, b, $P<0.001$ ). These results suggested that at least partial activity was conferred by bound zinc. Wild-type ALAD expressed along with isc operon and purified anaerobically (ALAD WT) did not contain zinc (Fig. 2a). Its enzymatic activity was approximately three times higher than that of aero-Zn-ALAD WT (Fig. 2b, compare the fourth bar versus the third bar). These results demonstrated that $\left[\mathrm{Fe}_{4} \mathrm{~S}_{4}\right]-\mathrm{ALAD}$ had significantly greater enzymatic activity than $\mathrm{Zn}$-ALAD.

To identify the AAs important for the coordination/acquisition of the $\left[\mathrm{Fe}_{4} \mathrm{~S}_{4}\right]$ cluster, we substituted each of the six highly conserved cysteines, and Lys252, which has been shown to form a Schiff base with the carbonyl of one of the two ALA substrates in the enzymatic active site (Supplementary Fig. 7) ${ }^{47}$. Additionally, we substituted the LYR-like motif of human ALAD with alanines. Thus, eight MBP-ALAD mutants (C119A, C122A, C124A, C132A, C162A, C223A, K252M, and Mut AFR-AAA) were generated. We expressed these mutants along with the bacterial isc operon and purified the overexpressed proteins anaerobically. To investigate whether the mutants coordinated a $\left[\mathrm{Fe}_{4} \mathrm{~S}_{4}\right]$ cluster, we plotted their molar extinction coefficients based on their UV-vis absorption spectra. As shown in Fig. 2c, none of UV-vis spectra of the mutants exhibited the absorption at $\sim 420 \mathrm{~nm}$, the hallmark feature of $\left[\mathrm{Fe}_{4} \mathrm{~S}_{4}\right]$ clusters. This observation indicated that these AAs were involved in either $\left[\mathrm{Fe}_{4} \mathrm{~S}_{4}\right]$ cluster coordination/acquisition or in maintaining the ALAD protein in a structure conducive to $\left[\mathrm{Fe}_{4} \mathrm{~S}_{4}\right]$ cluster coordination/acquisition. Importantly, the ALAD mutants all had significantly less iron and lower (or undetectable) enzymatic activities than ALAD WT (Fig. 2a, b, all $P$ values $<0.01$ ). These results further confirmed that the cysteines and AFR motif were important for $\left[\mathrm{Fe}_{4} \mathrm{~S}_{4}\right]$ cluster coordination/acquisition and the $\left[\mathrm{Fe}_{4} \mathrm{~S}_{4}\right]$ cluster was important for human ALAD enzymatic activity in vitro.

To determine whether the N-terminal MBP tag hindered the formation of a homo-octamer of ALAD subunits that constitutes the previously defined active form of $\mathrm{ALAD}^{10}$, and to assess how $\left[\mathrm{Fe}_{4} \mathrm{~S}_{4}\right]$ cluster coordination affected ALAD quaternary structure, the anaerobically purified wild-type and mutant ALAD proteins were subjected to native PAGE electrophoresis. As shown in Fig. 2d and Supplementary Fig. 8, most of the ALAD WT and aero-zincALAD WT monomers formed $\sim 640 \mathrm{kD}$ homo-octamers, while all the ALAD mutants and the aero-apo-ALAD WT mostly assembled into $\sim 480 \mathrm{kD}$ homo-hexamers, a previously identified less active multimeric state ${ }^{10}$. These results suggested that MBP-ALAD can form homo-octamers in vitro and that $\left[\mathrm{Fe}_{4} \mathrm{~S}_{4}\right]$ cluster coordination correlated with formation of higher proportions of ALAD homooctamers.

The $\left[\mathrm{Fe}_{4} \mathrm{~S}_{4}\right]$ cluster is important for ALAD activity in cells. Next, we investigated the biological significance of the $\left[\mathrm{Fe}_{4} \mathrm{~S}_{4}\right]$ cluster of ALAD in human HepG2 cells. We cotransfected HepG2 cells with siRNAs to knockdown (KD) the expression of endogenous ALAD, and used a plasmid to direct expression of either recombinant wild-type ALAD (the ALAD WT group) or the ALAD mutant in 
$\mathbf{a}$
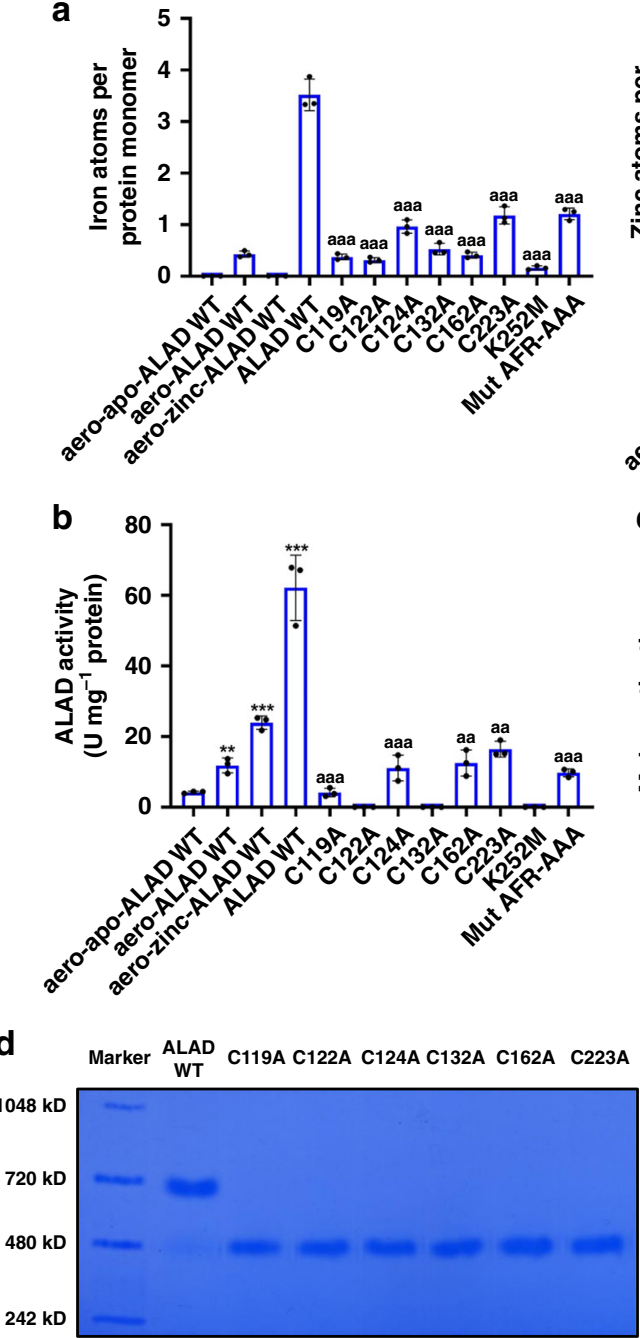

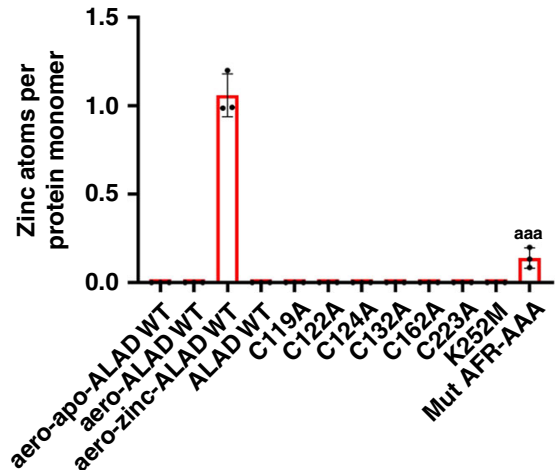

C
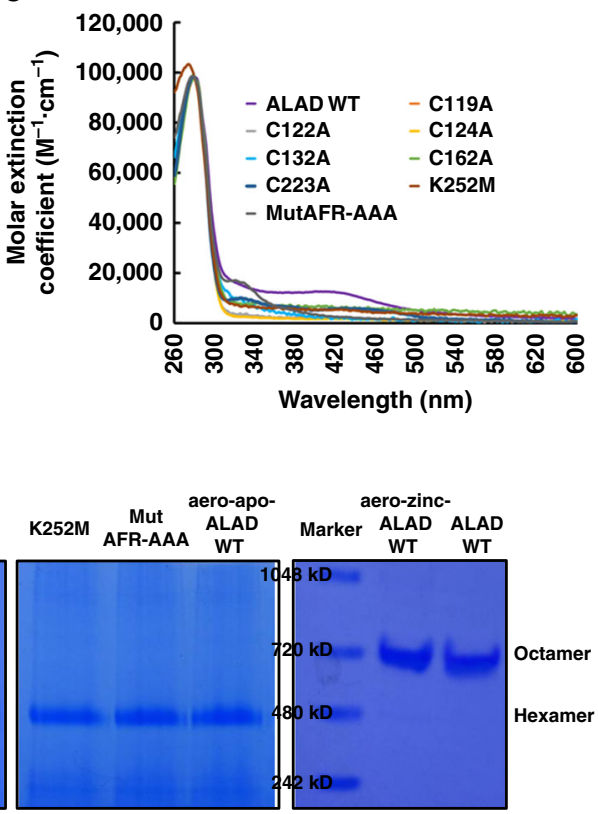

Fig. 2 The $\left[\mathrm{Fe}_{\mathbf{4}} \mathbf{S}_{\mathbf{4}}\right]$ cluster is important for ALAD enzymatic activity in vitro. a ICP-MS analysis and $\mathbf{b}$ Enzymatic activity of aerobically purified apo-ALAD (aero-apo-ALAD WT), aerobically purified zinc-ALAD (aero-Zn-ALAD WT) and the wild-type (ALAD WT) and mutant ALAD proteins expressed along with the isc operon in $E$. coli and purified anaerobically. Results indicate that the $\left[\mathrm{Fe}_{4} \mathrm{~S}_{4}\right]^{2+}$ cluster was important for the enzymatic activity of human ALAD in vitro. The data in panels $\mathbf{a}$ and $\mathbf{b}$ are presented as mean values \pm standard deviations of $n=3$ biologically independent samples. Two-sided unpaired Student's $t$-test was employed to analyze statistical significance. No multiple comparison was performed. ${ }^{\star \star},{ }^{\star \star \star}$ represent $P<0.01$ and $P<0.001$, respectively, versus the "aero-apo-ALAD WT" group; aa, aaa represent $P<0.01$ and $P<0.001$, respectively, versus the "ALAD WT" group. The exact $P$ values are provided in the Source Data file. c Molar extinction coefficients of C119A, C122A, C124A, C132A, C162A, C223A, K252M, and Mut AFR-AAA mutants that were expressed along with the isc operon in E. coli and purified anaerobically. The results indicated that $\mathrm{C} 119, \mathrm{C} 122, \mathrm{C} 124, \mathrm{C} 132, \mathrm{C} 162, \mathrm{C} 223$, and $\mathrm{K} 252$ of human $\left.\mathrm{ALAD}_{\text {were important for }[\mathrm{Fe}} \mathrm{S}_{4}\right]$ cluster coordination and/or retention, and the AFR motif was important for $\left[\mathrm{Fe}_{4} \mathrm{~S}_{4}\right]$ cluster acquisition. $\mathbf{d}$ Native gel electrophoresis analysis of wild-type and mutant ALAD proteins expressed along with the isc operon in $E$. coli and purified anaerobically, the aero-apo-ALAD WT protein, and aero-Zn-ALAD WT protein (See Supplementary Fig. 8 for the full Zn- ALAD WT native gel). This experiment was repeated three times independently with similar results. The results suggest that $\left[\mathrm{Fe}_{4} \mathrm{~S}_{4}\right]$ cluster coordination correlated with increased proportions of ALAD homo-octamers.

which the AFR motif had been replaced by alanines (Mut AFR-AAA group). Effective $\mathrm{KD}$ of endogenous ALAD was achieved in HepG2 cells (Fig. 3a). Recombinant ALAD WT or the Mut AFR-AAA mutant were well expressed with undetectable background expression of endogenous ALAD (Fig. 3a, b, $P$ values $<0.01$ compared with untransfected cells). We used ALAS1 protein levels and the activities of the heme-dependent enzymes, cytochrome P450 1A2 (CYP1A2) and catalase, as readouts of the integrity of the heme biosynthetic pathway ${ }^{48-50}$. As shown in Fig. 3a, d, e, respectively, there were no significant differences in the protein level of ALAS1 or in the catalase and CYP1A2 activities between the ALAD WT group and untransfected HepG2 cells. In cells expressing ALAD-Mut AFRAAA, however, we observed significantly decreased ALAD, catalase and CYP1A2 activities in cell lysates as compared with either untransfected HepG2 cells or cells expressing ALAD WT (Fig. 3a, c-e, $P$ values $<0.001)$. These results demonstrated that the AFR-AAA mutant was nonfunctional and exhibited significantly lower enzymatic activity than wild-type ALAD. Therefore, overexpression of ALAD-Mut AFR-AAA did not restore heme biosynthesis that was suppressed by siRNA-induced ALAD deficiency. Given that the AFR motif of human ALAD is required for $\left[\mathrm{Fe}_{4} \mathrm{~S}_{4}\right]$ cluster acquisition, these results demonstrated that the $\left[\mathrm{Fe}_{4} \mathrm{~S}_{4}\right]$ of human ALAD was important for its enzymatic activity and heme biosynthesis in HepG2 cells.

Finally, we examined whether zinc addition affected ALAD enzymatic activity by adding zinc to the medium of mammalian cells overexpressing either WT ALAD or the Mut AFR-AAA $(100 \mu \mathrm{M} \mathrm{ZnCl} 2$ for $48 \mathrm{~h})$. As shown in Fig. 3a, levels of human metallothionein MT2A, whose expression is regulated by zinc $^{51,52}$, were greatly increased, suggesting that levels of cellular 

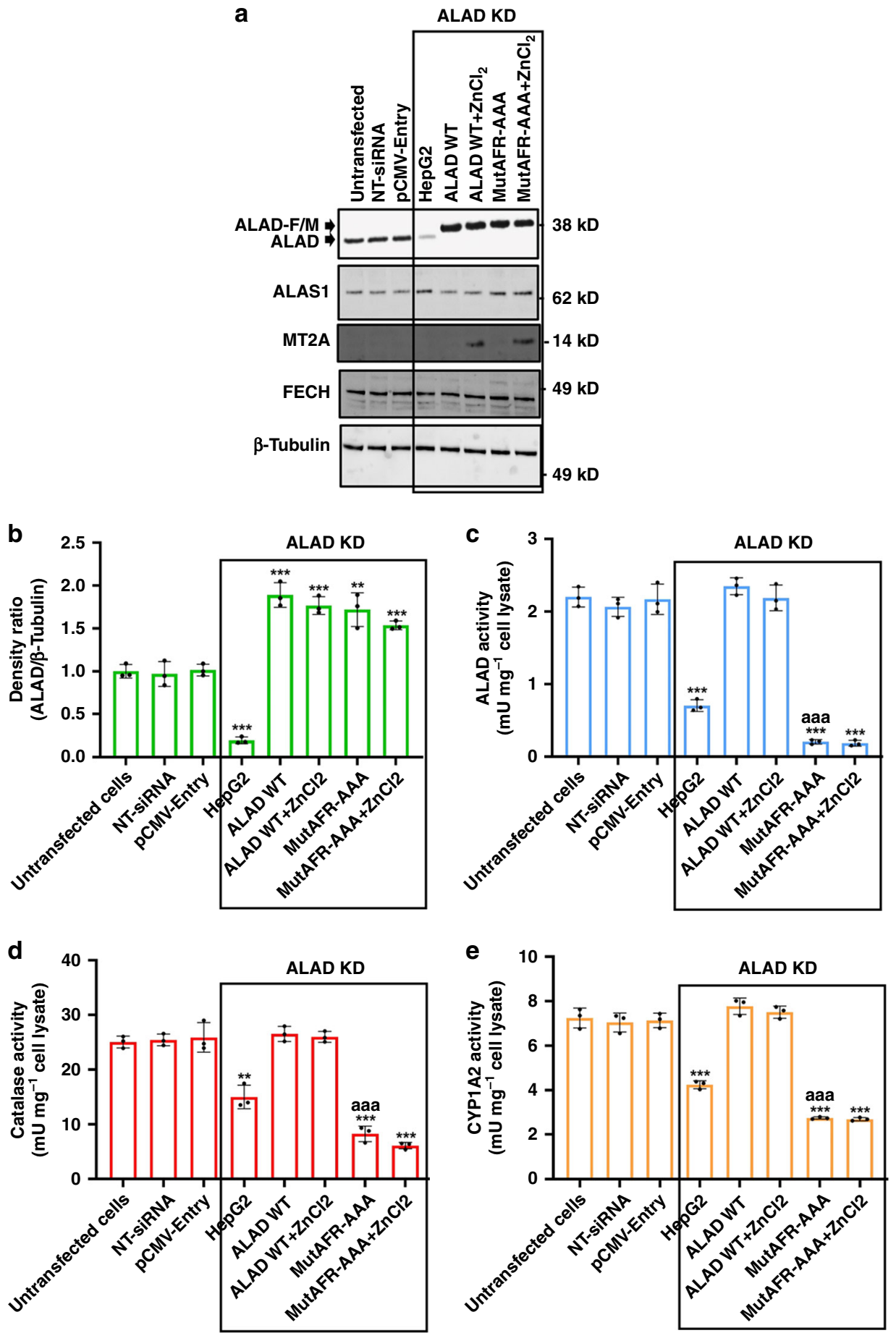

Fig. 3 The $\left[\mathrm{Fe}_{\mathbf{4}} \mathbf{S}_{\mathbf{4}}\right]$ cluster is important for ALAD activity in HepG2 cells. a Western blot analysis of protein levels of endogenous and exogenous $A L A D$, ALAS1, MT2A, and FECH in untransfected HepG2 cells, HepG2 cells transfected with nontargeting siRNA (NT-siRNA) or pCMV-Entry empty vector (pCMVEntry), ALAD deficient HepG2 cells (ALAD KD), HepG2 cells from the ALAD WT and Mut AFR-AAA groups without or with $100 \mu \mathrm{M}$ ZnCl 2 addition (ALAD $\mathrm{WT}$, ALAD WT $+\mathrm{ZnCl}_{2}$, Mut AFR-AAA or Mut AFR-AAA $+\mathrm{ZnCl}_{2}$, respectively). The experiments were repeated at least twice independently with similar results. $\mathbf{b}$ Densitometry of the ratios between the intensities of ALAD and the corresponding $\beta$-Tubulin protein levels. $\mathbf{c} A L A D, \mathbf{d}$ catalase, and $\mathbf{e}$ CYP1A2 activities in lysates of these cells. The data in panels $\mathbf{b}, \mathbf{c}, \mathbf{d}$, and $\mathbf{e}$ are presented as mean values \pm standard deviations of $n=3$ biologically independent samples. Two-sided unpaired Student's $t$-test was employed to analyze statistical significance. No multiple comparison was performed. ${ }^{\star \star}$, ${ }^{\star \star \star}$ represent $P<0.01$ and $P<$ 0.001 , respectively, versus "untransfected cells"; aaa represents $P<0.001$ versus the "ALAD WT" group. The exact $P$ values are provided in the Source Data file.

zinc indeed increased. However, there were no significant changes in either the protein levels of ALAS1 or the activity of ALAD, catalase or CYP1A2 after adding $\mathrm{ZnCl}_{2}$ to the medium (Fig. 3a, $\mathrm{c}-\mathrm{e})$. These results indicated that increasing intracellular zinc concentrations did not increase ALAD enzymatic activity in
HepG2 cells overexpressing either wild-type ALAD or the AFRAAA mutant. Notably, FECH protein levels were not affected by zinc addition, indicating that the coordination of $\left[\mathrm{Fe}_{2} \mathrm{~S}_{2}\right]$ cluster by human FECH was also unaffected by increased intracellular zinc levels (Fig. 3a). 


\section{Discussion}

In this study, we found that human ALAD requires a $\left[\mathrm{Fe}_{4} \mathrm{~S}_{4}\right]$ cluster for full enzymatic activity both in vitro and in HepG2 cells. More importantly, the $\left[\mathrm{Fe}_{4} \mathrm{~S}_{4}\right]$ cluster of ALAD is crucial for heme biosynthesis, unveiling a node of regulation of heme biosynthesis by ISC biogenesis that operates at the second step of the heme biosynthetic pathway.

To determine whether one or more steps of the cytosolic reactions of heme biosynthesis depended on Fe-S cluster biogenesis, we overexpressed a form of cytosolic ISCU that lacked a mitochondrial targeting signal and contained the mutation D46A, which prevents the ISCU scaffold from transferring its Fe-S cluster to recipient proteins in mammalian cells. Our results demonstrated that two heme-dependent enzymes, catalase and cytochrome P450 1A2, lost activity when the D46A ISCU construct was expressed to suppress cytosolic Fe-S biogenesis, as expected. We then used bioinformatics to evaluate whether the AA sequence of any of the cytosolic heme biosynthesis enzymes contained LYR-like motifs and potential cluster-ligating cysteines, which we have shown may represent features of candidate $\mathrm{Fe}-\mathrm{S}$ proteins ${ }^{30}$. Only human ALAD was found to contain an LYR-like motif, consisting of Ala306-Phe307-Arg308. LYR-like motifs are not rare in the human proteome, and only a subset of these motifs bind the cochaperone HSC20 to acquire an ISC, perhaps because of spatial and temporal issues brought about by the multiple compartments of mammalian cells. ALAD is expressed in the cytosol of mammalian cells, in proximity to active protein complexes that actively synthesize ISCs de novo, and it was therefore considered a strong potential candidate ${ }^{23}$. Moreover, ALAD had been previously characterized as a zinc protein, as ALAD purified from beef liver contained much larger amounts of zinc than iron $^{53}$, and zinc can often substitute for ISC ligation in proteins that have been exposed to oxygen, permitting the ISC to degrade. The low enzymatic activity of metal-free ALAD could be partially restored by zinc addition 53,54 , and in later studies, it was demonstrated that ALAD octamers required four zinc ions for enzymatic activity ${ }^{45}$. However, all these studies were performed under aerobic conditions that can interfere with identification of iron-sulfur clusters. In fact, many Fe-S proteins have been previously mischaracterized as zinc proteins, such as CPSF30 $0^{55}$, human CISD2 ${ }^{56}$, and yeast POL $3^{33}$. Therefore, we decided to explore whether ALAD is an Fe-S protein. According to our results, human ALAD could transiently bind the cochaperone HSC20, which is dedicated to ISC biogenesis, and can coordinate an ISC in human cells. In addition, each human ALAD monomer harbored one $\left[\mathrm{Fe}_{4} \mathrm{~S}_{4}\right]$ cluster when it was overexpressed in bacteria along with the isc operon and purified anaerobically.

We then compared the enzymatic activity of $\left[\mathrm{Fe}_{4} \mathrm{~S}_{4}\right]$-ALAD with that of zinc-ALAD and found that $\left[\mathrm{Fe}_{4} \mathrm{~S}_{4}\right]$-ALAD had significantly higher enzymatic activity than zinc-ALAD. ALAD catalyzes the asymmetric condensation of two ALA molecules to form porphobilinogen. The ALA molecule that becomes the propionyl side chain and pyrrole nitrogen-containing part of porphobilinogen is referred to as the P-side ALA, whereas that which contributes the acetyl side chain and amino nitrogencontaining part of porphobilinogen is known as the A-side ALA. According to previous studies, the first step of this enzymatic reaction is the formation of P-side Schiff base of ALA with the nitrogen of lysine 252, followed by A-side ALA binding to the other side of enzymatic active site pocket ${ }^{44,54,57-59}$. It was proposed that in zinc-ALAD, the zinc functioned as a Lewis acid to bind A-side $\mathrm{ALA}^{58}$. On the basis of the chemical similarity of the ALAD reaction to those catalyzed by the $\left[\mathrm{Fe}_{4} \mathrm{~S}_{4}\right]$-containing enzymes aconitase ${ }^{60}$, dihydroxyacid dehydratase ${ }^{61}$, and quinolinate synthase $e^{57,62}$, we initially posited that the $\left[\mathrm{Fe}_{4} \mathrm{~S}_{4}\right]$ cluster of ALAD might be coordinated by only three Cys ligands, permitting the non-Cys-coordinated iron to function as a Lewis acid and to coordinate the ALA substrate ${ }^{60,63}$. However, we found that neither the EPR nor the Mössbauer spectrum of $\left[\mathrm{Fe}_{4} \mathrm{~S}_{4}\right]$-ALAD (at the concentration of $250 \mu \mathrm{M}$ ) was perturbed by the addition of either $\sim 10 \mathrm{mM}$ ALA or $\sim 10 \mathrm{mM}$ succinylacetone, a potent ALAD inhibitor (Supplementary Fig. 6). The absence of perturbation of the $\left[\mathrm{Fe}_{4} \mathrm{~S}_{4}\right]$ cluster of ALAD upon addition of the substrate may be attributable to several unusual features of the enzyme. One is that the enzyme functions as an octamer, and it is not known how many monomeric subunits catalyze the enzymatic reaction at any given time. Interconnectedness between subunits implies that cooperativity and conformational changes are important ${ }^{64}$. Since $\left[\mathrm{Fe}_{4} \mathrm{~S}_{4}\right]$-ALAD mainly assembled into octamers and each monomer coordinated one $\left[\mathrm{Fe}_{4} \mathrm{~S}_{4}\right]$ cluster, it is conceivable that only a subset of the eight $\left[\mathrm{Fe}_{4} \mathrm{~S}_{4}\right]$ clusters of octameric ALAD bound the ALA substrate, and substrate/ product-coordinated forms of the enzyme failed to accumulate to a level detectable by Mössbauer spectroscopy. In fact, in the related enzyme, hydroxybutyryl-CoA dehydratase, there is no experimental evidence for coordination of the substrate to the non-cysteinyl-coordinated $\mathrm{Fe}$ site of its $\left[\mathrm{Fe}_{4} \mathrm{~S}_{4}\right]$ cluster ${ }^{65,66}$.

Interestingly, while the predominant oligomeric form of ALAD is that of a homo-octamer, a rare human $A L A D$ mutation that leads to substitution of phenylalanine 12 into leucine $\left(A L A D^{\mathrm{F} 12 \mathrm{~L}}\right)$ has been reported to cause a profound rearrangement of the enzyme oligomeric form, with a switch to the hexameric form that exhibited only $12 \%$ of residual activity compared with the octameric enzyme ${ }^{67,68}$. The significantly lower activity of the hexameric enzyme compared with that of the octameric ALAD points to a potential cooperative mechanism of catalysis that warrants additional investigations for a full understanding of the ALAD catalytic mechanism. In addition, given the high enzymatic activity of $\left[\mathrm{Fe}_{4} \mathrm{~S}_{4}\right]-\mathrm{ALAD}$, the condensation reaction of two ALA molecules into porphobilinogen catalyzed by the enzyme may already have been completed by the time the sample was frozen for Mössbauer and EPR analyses, which would leave the $\left[\mathrm{Fe}_{4} \mathrm{~S}_{4}\right]$-ALAD in the same $\left[\mathrm{Fe}_{4} \mathrm{~S}_{4}\right]$ coordination status as in the absence of the substrate. Finally, it is possible that the $\left[\mathrm{Fe}_{4} \mathrm{~S}_{4}\right]$ cluster of ALAD plays solely a structural role rather than a catalytic role. Thus, the role of the $\left[\mathrm{Fe}_{4} \mathrm{~S}_{4}\right]$ cluster in the enzymatic mechanism of ALAD remains an open question that will require insights into the role of octamerization and cooperativity of individual monomers for further analysis.

Most $\mathrm{Fe}-\mathrm{S}$ proteins coordinate their clusters through cysteines ${ }^{17,69}$. To identify the cysteines important for $\left[\mathrm{Fe}_{4} \mathrm{~S}_{4}\right]$ cluster acquisition and/or coordination, we mutagenized the six highly conserved cysteines of human ALAD to alanine residues (A). According to previous studies, lysine 263 (K263) in yeast ALAD, which corresponds to K252 in human ALAD, forms Schiff base with one of the two molecules of ALA to facilitate the condensation reaction ${ }^{47,70}$. Therefore, we also mutagenized K252 in human ALAD to methionine to investigate the impact of a $\mathrm{K} 252 \mathrm{M}$ mutant on $\left[\mathrm{Fe}_{4} \mathrm{~S}_{4}\right]$ cluster coordination and ALAD enzymatic activity. To examine the biological significance of the AFR motif, we substituted the $\mathrm{F}$ and $\mathrm{R}$ residues with alanines to generate Mut AFR-AAA. According to our results, all the amino acid residues investigated are important for $\left[\mathrm{Fe}_{4} \mathrm{~S}_{4}\right]$ cluster coordination and the enzymatic activity of human ALAD in vitro. Our findings are consistent with those of a previous study in which a combination of $\mathrm{C} 122 \mathrm{~A}, \mathrm{C} 124 \mathrm{~A}$ and $\mathrm{C} 132 \mathrm{~A}$ greatly reduced activity of human ALAD that ligates zinc ${ }^{45}$. In both the zinc-containing form of the enzyme which can be generated in vitro, and the Fe-S-containing form detected after overexpression in bacteria, cysteines 122, 124, and 132 appear to be required for acquisition of enzymatic activity. Consistent with these findings, a Cys132Arg mutation was found to be responsible 
for ALAD porphyria in a 14-year-old boy ${ }^{71}$. Furthermore, we speculate that the structure of ALAD with a $\left[\mathrm{Fe}_{4} \mathrm{~S}_{4}\right]$ cluster may resemble the crystal structure of Zn-ALAD (Supplementary Fig. 7) ${ }^{46}$, and Cys residues 122, 124, and 132, the $\mathrm{Zn}$ (II) ligands in the published structures of ALAD ${ }^{46}$, might coordinate the $\left[\mathrm{Fe}_{4} \mathrm{~S}_{4}\right]$ cofactor, potentially leaving an open Fe ligand site $e^{40,60,63}$. Cys119 and Cys162 are located on two parallel beta-strands (Supplementary Fig. 7) in positions where they have been proposed to form a disulfide bond that stabilizes ALAD tertiary structure ${ }^{45}$. Therefore, mutagenesis of the cysteine residues that ligate zinc in the available crystal structure may directly affect ISC ligation, whereas mutagenesis of $\mathrm{C} 119$ and $\mathrm{C} 162$ can impair cluster ligation as a result of misfolding of ALAD. The negative effects on ALAD activity and Fe-S cluster coordination caused by mutagenesis of C223 can be explained on the basis of published structure of the zinc-binding form of the enzyme, in which C223 protrudes at the interface between adjacent monomers, likely contributing to ALAD oligomerization by contacting residues on the adjacent protomer ${ }^{44}$. An alternative possibility is that C223 may represent the fourth cysteine residue ligating the Fe-S cluster, given its proximity to $\mathrm{C} 122, \mathrm{C} 124$, and $\mathrm{C} 132$ (Supplementary Fig. 7). Notably, the K252M mutant completely lost its enzymatic activity, as expected based on the observation that it forms a Schiff base to bind ALA substrate ${ }^{47,70}$. We speculate that binding of one of the two ALA molecules, which are condensed to form porphobilinogen in the "active site pocket" as previously defined, was lost ${ }^{47,70}$, but Fe-S ligation was also notably absent as well for unclear reasons.

The quaternary structure of human ALAD can switch between a homo-hexameric and a homo-octameric configuration ${ }^{10}$. Wild-type ALAD monomers tend to form a homo-octamer with full enzymatic activity through interactions between their $\mathrm{N}$ terminal domains ${ }^{10,72}$. In the presence of $A L A D$ mutations or of "morphlocks", small molecules that stabilize specific quaternary structures, ALAD can assemble into a homo-hexameric configuration with lower enzymatic activity than the homo-octameric configuration ${ }^{72,73}$. In this study, we found that $\left[\mathrm{Fe}_{4} \mathrm{~S}_{4}\right]$ cluster coordination correlated with increased proportions of ALAD homo-octamers, which may be another reason why $\left[\mathrm{Fe}_{4} \mathrm{~S}_{4}\right]$ ALAD has high enzymatic activity.

Finally, we explored the biological significance of the $\left[\mathrm{Fe}_{4} \mathrm{~S}_{4}\right]$ cluster of ALAD in human HepG2 cells. We performed functional assays to investigate whether overexpression of either wildtype human ALAD or the AFR-AAA mutant could rescue the heme biosynthetic defect of ALAD-knockdown cells. According to our results, the $\left[\mathrm{Fe}_{4} \mathrm{~S}_{4}\right]$ of human ALAD was important for its enzymatic activity and heme biosynthesis in HepG2 cells. Interestingly, we also found that increased intracellular zinc concentrations, achieved by adding $\mathrm{ZnCl}_{2}$ into the cell culture medium, did not increase ALAD enzymatic activity in wild-type ALAD- or AFR-AAA mutant-overexpressing HepG2 cells, suggesting that mammalian cells lack mechanisms that specifically deliver zinc to ALAD in growing cells.

In conclusion, our findings have several important biological implications. In iron-deficient non-erythroid cells, reduced ISC availability should decrease the enzymatic activity of ALAD, diminishing the potential accumulation of pyrroles and porphyrins synthesized downstream of ALAD that could otherwise occur in conjunction with reduced holo-FECH levels and/or increased ALAS1 protein levels. Porphyrin intermediates are toxic, and their accumulation causes several types of human porphyria ${ }^{74-76}$. Therefore, the regulation of ALAD activity by ISC biogenesis may represent a mechanism that prevents iron- or ISC-deficient non-erythroid cells from accumulating harmful heme metabolic intermediates. In addition, given that Fe-S clusters are sensitive to oxidative stress ${ }^{17}$ and that ALAD was shown to be a direct target of oxidative stress ${ }^{77}$, we speculate that oxidative damage of the $\left[\mathrm{Fe}_{4} \mathrm{~S}_{4}\right]$ of human ALAD may be implicated in pathological conditions associated with both increased oxidative stress and anemia, such as chronic renal failure ${ }^{78}$. Furthermore, since we confirmed the biological significance of a LYR or LYR-like motif, our study supports our model that enzymes unrelated to the mitochondrial respiratory chain depend on $\mathrm{Fe}-\mathrm{S}$ delivery from a cochaperone/chaperone pathway that is critical for $\mathrm{Fe}-\mathrm{S}$ acquisition ${ }^{28}$. Our work validates our previous prediction $^{30}$ that novel Fe-S proteins may be identified prospectively based on presence of LYR motifs in proteins that contain enough cysteine ligands to coordinate a Fe-S cluster, particularly if the protein has been previously characterized as a zinc-binding protein $^{30}$.

\section{Methods}

Plasmids and mutagenesis. Plasmids used in this study were customized and purchased from GenScript. The mutations in human ALAD gene were introduced using the Phusion Site-Directed Mutagenesis Kit (ThermoFisher Scientific) with polymerase chain reaction (PCR) primers listed in Supplementary Table 1 of the Supplementary Information (SI) file.

Cell lines and culturing methods. In this study, we used different cell lines for different experiments because heme biosynthesis is a ubiquitous process occurring in all the cell lines and each cell line has characteristics that allow it to perform better in the corresponding experiment. Also, since there is only one known form of endogenous ALAD in all the cell lines used and that we sequenced all the ALADexpressing plasmids to make sure they express the correct protein, we confirm that we are working with the same protein, human ALAD, in all of our experiments. All the cell lines used in this study were subjected to mycoplasma testing.

We used HeLa cells (ATCC) for investigating the endogenous interaction between HSC20 and ALAD and the interactions between endogenous HSC20 and overexpressed FLAG/MYC-tagged wild-type ALAD or FLAG/MYC-tagged AFRAAA ALAD mutant. For investigating whether FECH was the only iron-sulfur protein involved in heme biosynthesis, we used HepG2 cells (ATCC) and previously established HEK293T cell lines stably transfected with pLVX-TetOne empty vector, or with pLVX-TetOne-ISCU1-MYC or pLVX-TetOne-ISCU1-D46A mutant-MYC, which expressed MYC-tagged wild-type cytosolic ISCU (ISCU1) or the dominant negative mutant ISCU1-D46A, respectively, under the control of a doxycycline inducible promote ${ }^{23}$. Transgene expression was induced by addition of $2 \mu \mathrm{g} / \mathrm{mL}$ of doxycycline to the growth medium, and cells were harvested and extracted $24 \mathrm{~h}$ later. To investigate the biological significance of the $\left[\mathrm{Fe}_{4} \mathrm{~S}_{4}\right]$ cluster of ALAD, we used HepG2 cells. To evaluate ${ }^{55} \mathrm{Fe}$ incorporation into C-terminally FLAG/MYC-tagged POLD1, ALAD WT, and Mut AFR-AAA, we used HEK293 cells (ATCC). To investigate whether human ALAD can coordinate an iron-sulfur cluster in human cells, we overexpressed C-terminally FLAG/MYC-tagged wildtype ALAD and FLAG/MYC-tagged AFR-AAA ALAD mutant in Expi293 cells (ThermoFisher Scientific). The HeLa and HepG2 cells were maintained in Eagle's minimum essential medium (EMEM) supplemented with $10 \%$ fetal bovine serum (Gibco, USA) and penicillin-streptomycin (Gibco, USA). The stable inducible HEK293T cells expressing ISCU1 wild-type or mutant were maintained in Dulbecco's Modified Eagle Medium (DMEM), supplemented with $10 \%$ of tetracycline-free FBS (Clontech), $2 \mathrm{mM}$ glutamine and $0.25 \mu \mathrm{g} / \mathrm{mL}$ of puromycin. The HEK293 cells were propagated in Dulbecco's modified Eagle's medium (DMEM) with $4.5 \mathrm{~g} / \mathrm{L}$ glucose, supplemented with $10 \%$ fetal bovine serum (FBS) and $2 \mathrm{mM}$ glutamine. The Expi293 cells were propagated and transfected according to the manufacturer's instructions. All the cells were cultured at $37^{\circ} \mathrm{C}, 5 \% \mathrm{CO}_{2}$ in a humidified cell culture incubator.

Cell transfection and zinc treatment. HeLa cells were seeded at $\sim 4 \times 10^{6}$ cells per $10-\mathrm{cm}$ cell culture plate one day before transfection. The next day, cells were transfected with pCMV6-ALAD wild-type-FLAG/MYC, which directs expression of C-terminally FLAG/MYC-tagged wild-type ALAD protein, or pCMV6-ALADMut AFR-AAA-FLAG/MYC, which directs expression of C-terminally FLAG/ MYC-tagged AFR-AAA ALAD mutant, using the Lipofectamine 2000 Reagent (Invitrogen) according to the protocol provided by the manufacturer. The cells were harvested for downstream analyses $\sim 48 \mathrm{~h}$ after transfection.

HepG2 cells were seeded at $\sim 3 \times 10^{6}$ cells per $10-\mathrm{cm}$ cell culture plate one day before transfection. The next day, cells were transfected with the ALAD siRNA pool (Dharmacon), the ISCU siRNA pool (Dharmacon), or the combinations of ALAD siRNA+ pCMV6-ALAD wild-type-FLAG/MYC, ALAD siRNA+ pCMV6ALAD-Mut AFR-AAA-FLAG/MYC, or ISCU siRNA+ pCMV6-yeast FECHFLAG/MYC (which directs expression of C-terminally FLAG/MYC-tagged yeast FECH). HepG2 cells transfected with a nontargeting siRNA or the pCMV6-Entry empty vector were the negative controls. The transfected HepG2 cells were cultured for $48 \mathrm{~h}$ before they were subjected to a second round of transfections with the 
same siRNAs, plasmids or siRNA+plasmid combinations. All the transfections were performed using the Lipofectamine RNAiMAX Reagent (Invitrogen) according to the manufacturer's instructions.

On-TARGETPlus siRNA pools against human ISCU (L-012837-01-0005) and the control nontargeting pool (D-001810-10-05) were purchased from Dharmacon. Knockdown of ISCU in HEK293 cells was achieved by transfecting the cells twice with siRNAs at a 48-h interval using Dharmafect 1 according to manufacturer's instructions. Cell lysates were analyzed $48 \mathrm{~h}$ after the second transfection.

To test the effect of zinc addition on ALAD activity, $100 \mu \mathrm{M} \mathrm{ZnCl} 2$ was added to the HepG2 cells transfected with the combinations of ALAD siRNA+ pCMV6ALAD wild-type-FLAG/MYC and ALAD siRNA+ pCMV6-ALAD-Mut AFRAAA-FLAG/MYC $24 \mathrm{~h}$ after the first round of transfections. The cells were collected $72 \mathrm{~h}$ after the first round of transfections.

\section{Cell fractionation and anaerobic purification of recombinant wild-type and} mutant ALAD from mammalian cells. Organelle and cytosolic fractions were separated with the Mitochondria Isolation Kit (ThermoFisher) according to the manufacturer's protocol.

Immunoprecipitations of recombinant FLAG/MYC-tagged POLD1 (POLD1) wild-type ALAD (ALAD WT), or ALAD mutant of the AFR motif (Mut AFRAAA) were performed on cytosolic fractions from HEK293 or Expi293 cells in a nitrogen recirculated glove box operated at $<0.2 \mathrm{ppm} \mathrm{O}_{2} 48 \mathrm{~h}$ after transfection with plasmids encoding POLD1, ALAD WT, or Mut AFR-AAA. Anti-FLAG immunoprecipitations were performed using M2-FLAG beads (Sigma). Washed FLAG M2 beads were added to the lysate and incubated for $2 \mathrm{~h}$ at room temperature under mild agitation. After the beads were recovered, recombinant proteins were competitively eluted with $100 \mu \mathrm{g} / \mathrm{ml} 3 \times$ FLAG peptide (Sigma).

UV-vis spectra were acquired using a NanoDrop spectrophotometer (ThermoFisher) using a column buffer supplemented with $100 \mu \mathrm{g} / \mathrm{ml} 3 \times$ FLAG peptide as the blank.

${ }^{55} \mathrm{Fe}$ incorporation assay. HEK293 cells were grown in the presence of $1 \mu \mathrm{M}{ }^{55} \mathrm{Fe}-$ Tf and transfected twice at $48 \mathrm{~h}$ interval with siRNAs targeting ISCU or with nontargeting siRNAs. At the time of the second transfection with siRNAs, cells were cotransfected with FLAG/Myc-tagged ALAD WT or Mut AFR-AAA, or with FLAG/Myc-tagged POLD1, which was included in the experiment as a positive control. Cytosolic extracts were prepared in the glove box after the second transfection and subjected to immunoprecipitation with anti-FLAG M2 agarose beads.

${ }^{55} \mathrm{Fe}$ incorporation into recombinant proteins was measured by scintillation counting of FLAG beads after immunoabsorption of FLAG-tagged recombinant proteins, followed by extensive washings with buffer I $25 \mathrm{mM}$ Tris, $0.15 \mathrm{M} \mathrm{NaCl}$, $1 \mathrm{mM}$ EDTA, $1 \% \mathrm{NP}-40,5 \%$ glycerol (pH 7.4), protease and phosphatase inhibitor cocktail with no EDTA (Roche)]. The background, corresponding to ${ }^{55} \mathrm{Fe}$ measurements of eluates after anti-FLAG immunoprecipitations on cytosolic extracts from cells transfected with the empty vector (pCMV6-Entry; Origene), was subtracted from each reading.

\section{Overexpression and anaerobic purification of maltose-binding protein (MBP)- tagged human ALAD proteins. BL21(DE3) competent bacterial cells (NEB) were} cotransformed with pDB1282, a plasmid directing expression of the isc operon from Azotobacter vinelandii, which consists of bacterial IscS (the bacterial homolog of human NFS1), IscU (the bacterial homolog of ISCU) and IscA (both of which provide scaffolds for iron-sulfur cluster assembly), Fdx (which plays the role of human FDXs by providing reducing equivalents), and $\mathrm{HscA}$ and $\mathrm{HscB}$ (which have functions corresponding to those of the human chaperone-cochaperone pair, HSPA9 and HSC20, respectively), and pMALc5x-MBP-ALAD plasmids, which directs expression of N-terminally MBP-tagged wild-type or mutant human ALAD proteins. The cotransformants were then used to inoculate $1 \mathrm{~L}$ Terrific Broth (TB) medium supplemented with $0.2 \%$ glucose and $1 \%$ glycerol. After growth at $37^{\circ} \mathrm{C}$ for $3-4 \mathrm{~h}$ to an optical density at $600 \mathrm{~nm}\left(\mathrm{OD}_{600}\right)$ of $0.5-0.7$, the culture was cooled to $\sim 15^{\circ} \mathrm{C}$. It was then supplemented with $100 \mu \mathrm{M} \mathrm{IPTG}, 0.2 \% \mathrm{~L}$-(+)-arabinose (Sigma), $300 \mu \mathrm{M} \mathrm{L}$-cysteine and $40 \mu \mathrm{M} \mathrm{FeCl}{ }_{3}$ or ${ }^{57} \mathrm{FeCl}_{3}$ (for Mössbauer analysis) and cultured at $15^{\circ} \mathrm{C}$ for $16-18 \mathrm{~h}$ with shaking at $140 \mathrm{rpm}$. The cells were harvested by centrifugation at $14,000 \times g$ and $4^{\circ} \mathrm{C}$ and were lysed with the BugBuster ${ }^{\circledR}$ Protein Extraction Reagent (Novagen) supplemented with the rLysozyme ${ }^{\text {rm }}$ Solution (Sigma Millipore), Benzonase ${ }^{\star}$ Nuclease (Sigma Millipore) and cOmplete ${ }^{\mathrm{me}}$, EDTA-free Protease Inhibitor (Sigma Millipore) in a nitrogen recirculated glove box operated at $<0.2 \mathrm{ppm} \mathrm{O}_{2}$. The N-terminally MBP-tagged ALAD proteins in the bacterial lysates were captured by amylose resin (NEB) and eluted with $10 \mathrm{mM}$ maltose in column buffer ( $20 \mathrm{mM}$ Tris-HCl, $\mathrm{pH} 8.0$, and $200 \mathrm{mM} \mathrm{NaCl}$ in deionized water).

\footnotetext{
Ultraviolet-visible (UV-vis) spectroscopy, inductively coupled plasma mass spectrometry (ICP-MS), amino acid analysis (AAA), electron paramagnetic resonance (EPR) spectroscopy, and Mössbauer spectroscopy. Uv-vis spectra were acquired using a NanoDrop spectrophotometer (ThermoFisher) with column buffer supplemented with $10 \mathrm{mM}$ maltose being used as the blank. For ICP-MS, $25 \mu \mathrm{L}$ sample was digested overnight and iron and zinc concentrations were determined with an Agilent 7900 ICP-MS system. AAA was performed by Alphalyse to precisely quantify the purified ALAD proteins. To verify the presence
}

of an iron-sulfur cluster, the anaerobically purified MBP-ALAD $(250 \mu \mathrm{M})$ was subjected to both EPR and Mössbauer analyses.

To verify the presence of iron-sulfur cluster(s), Mössbauer and EPR analyses were carried out. For Mössbauer analysis, a $330 \mu \mathrm{L}$ aliquot of anaerobically purified, ${ }^{57} \mathrm{Fe}$ enriched, wild-type (wt) ALAD $(250 \mu \mathrm{M})$ was transferred into a Mössbauer cup and frozen by placing it on an aluminum block precooled in $\mathrm{LN}_{2}$. In order to assess if binding of the substrate (ALA) or the inhibitor (SA) perturbs the Mössbauer spectrum of the $\left[\mathrm{Fe}_{4} \mathrm{~S}_{4}\right]^{2+}$ clusters, two aliquots $\left(330-\mu \mathrm{L}\right.$ each) of ${ }^{57} \mathrm{Fe}-$ wt-ALAD $(250 \mu \mathrm{M})$ were mixed with $33 \mu \mathrm{L}$ of $100 \mathrm{mM}$ ALA and SA, respectively. The reaction mixtures were subsequently transferred into two Mössbauer cups and frozen as already described. The reaction time between the time of addition of substrates to the time of freezing is $\sim 4$ min. Mössbauer spectra were recorded on an alternating constant acceleration Mössbauer spectrometer from SEE Co. (Edina, MN) equipped with a Janis SVT-400 variable-temperature cryostat. The external $53 \mathrm{mT}$ magnetic field was oriented parallel to the direction of propagation of the $\gamma$ beam. All isomer shifts are quoted relative to the centroid of the spectrum of $\alpha$-iron metal at room temperature. Simulation of the Mössbauer spectra was carried out using the WMOSS spectral analysis software (www.wmoss.org; Seeco Research, Edina, $\mathrm{MN}$ ).

For EPR analysis, a $150 \mu \mathrm{L}$ aliquot of anaerobically purified wild-type ALAD $(250 \mu \mathrm{M})$ was transferred into an EPR tube and frozen in liquid nitrogen $\left(\mathrm{LN}_{2}\right)$. To test if ALA or SA binding causes any perturbation to the one electron reduced $\left[\mathrm{Fe}_{4} \mathrm{~S}_{4}\right]^{+}$cluster in ALAD, we prepared three parallel samples with a final ALAD concentration of $150 \mu \mathrm{M}$. $\mathrm{Na}_{2} \mathrm{~S}_{2} \mathrm{O}_{4}$ (final concentration $=2.5 \mathrm{mM}$ ) was added to all the samples and incubated for 5 mins. To two of the three samples were added either ALA or SA (final concentrations $=10 \mathrm{mM}$ ) before transferring them into two separate EPR tubes and being frozen in $\mathrm{LN}_{2}$. The reaction time of the dithionite-reduced ALAD with substrates (ALA or SA), from the time of mixing to the time of being frozen, is $\sim 3 \mathrm{~min}$. The continuous-wave EPR (CW-EPR) spectrum was acquired on an ESP300 Bruker X-band spectrometer equipped with an ER 410ST resonator. The temperature was controlled by an ER 4112-HV Oxford Instruments (Concord, MA) variable-temperature helium flow cryostat Acquisition and control of experimental parameters were performed using EWIN 2012 software on an external personal computer via a GPIB interface. The conversion time and the time constant were $40.96 \mathrm{~ms}$; the modulation amplitude was $5 \mathrm{G}$; the microwave frequency was $9.621 \mathrm{GHz}$; and the microwave power was $20 \mathrm{~mW}$. Spectra were averaged over 10 scans.

Preparation of apo-ALAD and zinc-bound ALAD. Aerobically purified human ALAD was treated with $10 \mathrm{mM}$ EDTA for one hour and passed through a G-25 column (GE Healthcare) to yield metal-free ALAD (apo-ALAD). For zinc reconstitution, apo-ALAD was incubated with $5 \mathrm{mM}$ dithiothreitol and 20 equivalents of $\mathrm{ZnCl}_{2}$ at room temperature for two hours and subsequently passed through a G-25 column.

Western blotting, co-immunoprecipitation, and native gel electrophoresis Organelle and cytosolic fractions were lysed with M-PER ${ }^{\circ}$ Protein Extraction Reagent (ThermoFisher). For western blotting, $20-40 \mu \mathrm{g}$ protein sample was used. Mouse monoclonal anti-FLAG antibody was from OriGene, anti-ISCU rabbit polyclonal serum was raised against a synthetic peptide fragment, as previously reported ${ }^{25}$; anti $\alpha$-TUB antibody was from Sigma. All the other primary antibodies for western blotting were from Abcam.

To investigate the endogenous interaction between human ALAD and HSC20, rabbit anti-HSC20 antibody (Sigma) was coupled onto the amine-reactive resin. To investigate the interactions between endogenous HSC20 and overexpressed FLAG/ MYC-tagged wild-type ALAD or FLAG/MYC-tagged AFR-AAA ALAD mutant, EZview $^{\text {mit }}$ Red ANTI-FLAG ${ }^{\oplus}$ M2 Affinity Gel (Sigma) was used. Cytosolic fractions and whole-cell lysates of HeLa cells were incubated with the anti-HSC20 antibodycoupled resin or the anti-FLAG beads at $4{ }^{\circ} \mathrm{C}$ overnight, and bound proteins were collected by acidic elution (Tris-glycine, $\mathrm{pH}$ 2.8). The eluates were then subjected to western blotting with anti-HSC20 and anti-ALAD antibodies (Abcam). Coimmunoprecipitation with rabbit IgG served as a negative control, and aliquots corresponding to $5-10 \%$ of HeLa cytosolic fractions or whole-cell lysates were used as inputs.

For native gel electrophoresis, anaerobically purified ALAD proteins were separated, and the bands were visualized using the NativePAGE ${ }^{\mathrm{si}}$ Bis-Tris Gel System (ThermoFisher) according to the manufacturer's instructions.

Antibody information. In this study, we used the following antibodies for Western blotting and co-immunoprecipitation experiments: rabbit anti-ALAD (1:1000, Abcam ab59013); rabbit anti-ALAS1 (1:500, Abcam ab84962); rabbit anti-FECH (1:500, Abcam ab137042); mouse anti-TOMM20, (1:2000, Abcam ab56783); mouse anti- $\beta$-Tubulin, (1:2000, Sigma T8328); mouse anti- $\alpha$-Tubulin, (1:2000, Sigma T5168); rabbit anti-HSC20, (1:50 for Co-IP experiments, Sigma HPA018447); mouse anti-HSC20, (1:1000, OriGene TA507285); mouse anti-FLAG Tag, (1:100 for Co-IP experiments, Genscript A00187); rabbit anti-MT2A, (1:200, LifeSpan Bio LS-C667906-50); mouse anti-FLAG, (1:2000, OriGene TA50011-100); rabbit antiISCU antibody, (1;1000, prepared in our lab). 
ALAD, cytochrome P450 (CYP), and catalase activity assays. ALAD activity was determined according to a published protocol ${ }^{79}$. Briefly, $50 \mu \mathrm{l}(1 \mu \mathrm{g} / \mu \mathrm{l})$ of purified ALAD proteins or freshly prepared cell lysates were added into a reaction system containing $238 \mu \mathrm{l}$ of ice-cold Tris-acetate buffer $(100 \mathrm{mM}, \mathrm{pH} 7.2)$ and $12 \mu \mathrm{l}$ of $100 \mathrm{mM}$ ALA-HCl. The mixtures were incubated at $37^{\circ} \mathrm{C}$ for $10 \mathrm{~min}$ (for purified ALAD proteins) or one hour (for cell lysates). The reactions were terminated by adding $300 \mu \mathrm{l}$ of $10 \%$ trichloroacetic acid/ $0.1 \mathrm{M} \mathrm{HgCl}_{2}$ and the amounts of generated porphobilinogen were quantified using the modified Ehrlich's reagent. The CYP1A2 and catalase activities were analyzed by the CYP1A2 Activity Assay Kit (Abcam) and Catalase Activity Assay Kit (Abcam), respectively.

Statistics. Image J v1.46 was used to analyze band intensity of western blotting. Where applicable, three independent replicates (four independent replicates for the ${ }^{55} \mathrm{Fe}$ incorporation experiments) were performed, and results are presented as mean \pm standard deviation (S.D.) using the Microsoft Excel 2016 Two-sided unpaired Student's $t$-test was used to determine the $P$ value using GraphPad Prism 8. $P<0.05, P<0.01$, and $P<0.001$ were considered significant ( ${ }^{*}$ or ${ }^{a}$ ), very significant $(* *$ or aa) and extremely significant $(* * *$ or aaa), respectively.

Reporting summary. Further information on research design is available in the Nature Research Reporting Summary linked to this article.

\section{Data availability}

All the data reported in this study are available upon reasonable request. Source data are provided with this paper.

Received: 23 June 2020; Accepted: 6 November 2020;

Published online: 09 December 2020

\section{References}

1. Muckenthaler, M. U., Rivella, S., Hentze, M. W. \& Galy, B. A red carpet for iron metabolism. Cell 168, 344-361 (2017).

2. Kafina, M. D. \& Paw, B. H. Intracellular iron and heme trafficking and metabolism in developing erythroblasts. Metallomics 9, 1193-1203 (2017).

3. Ponka, P. Tissue-specific regulation of iron metabolism and heme synthesis: distinct control mechanisms in erythroid cells. Blood 89, 1-25 (1997).

4. Ajioka, R. S., Phillips, J. D. \& Kushner, J. P. Biosynthesis of heme in mammals. Biochim. Biophys. Acta 1763, 723-736 (2006).

5. Schultz, I. J., Chen, C. Y., Paw, B. H. \& Hamza, I. Iron and porphyrin trafficking in heme biogenesis. J. Biol. Chem. 285, 26753-26759 (2010).

6. Rouault, T. A. \& Maio, N. Biogenesis and functions of mammalian iron-sulfur proteins in the regulation of iron homeostasis and pivotal metabolic pathways. J. Biol. Chem. 292, 12744-12753 (2017).

7. Ye, H. et al. Glutaredoxin 5 deficiency causes sideroblastic anemia by specifically impairing heme biosynthesis and depleting cytosolic iron in human erythroblasts. J. Clin. Invest. 120, 1749-1761 (2010).

8. Kubota, Y. et al. Novel mechanisms for heme-dependent degradation of ALAS1 protein as a component of negative feedback regulation of heme biosynthesis. J. Biol. Chem. 291, 20516-20529 (2016).

9. Zheng, J., Shan, Y., Lambrecht, R. W., Donohue, S. E. \& Bonkovsky, H. L. Differential regulation of human ALAS1 mRNA and protein levels by heme and cobalt protoporphyrin. Mol. Cell Biochem. 319, 153-161 (2008).

10. Jaffe, E. K. The porphobilinogen synthase family of metalloenzymes. Acta Crystallogr. D. Biol. Crystallogr. 56, 115-128 (2000).

11. Battersby, A. R. Tetrapyrroles: the pigments of life. Nat. Prod. Rep. 17, 507-526 (2000).

12. Dailey, H. A., Finnegan, M. G. \& Johnson, M. K. Human ferrochelatase is an iron-sulfur protein. Biochemistry 33, 403-407 (1994).

13. Wu, C. K. et al. The $2.0 \mathrm{~A}$ structure of human ferrochelatase, the terminal enzyme of heme biosynthesis. Nat. Struct. Biol. 8, 156-160 (2001).

14. Dailey, H. A. et al. Ferrochelatase at the millennium: structures, mechanisms and [2Fe-2S] clusters. Cell Mol. Life Sci. 57, 1909-1926 (2000).

15. Crooks, D. R., Ghosh, M. C., Haller, R. G., Tong, W. H. \& Rouault, T. A. Posttranslational stability of the heme biosynthetic enzyme ferrochelatase is dependent on iron availability and intact iron-sulfur cluster assembly machinery. Blood 115, 860-869 (2010).

16. Maio, N. \& Rouault, T. A. Iron-sulfur cluster biogenesis in mammalian cells: new insights into the molecular mechanisms of cluster delivery. Biochim. Biophys. Acta 1853, 1493-1512 (2015).

17. Beinert, H., Holm, R. H. \& Munck, E. Iron-sulfur clusters: nature's modular, multipurpose structures. Science 277, 653-659 (1997).

18. Broderick, J. B., Duffus, B. R., Duschene, K. S. \& Shepard, E. M. Radical Sadenosylmethionine enzymes. Chem. Rev. 114, 4229-4317 (2014).
19. Booker, S. J. Anaerobic functionalization of unactivated C-H bonds. Curr. Opin. Chem. Biol. 13, 58-73 (2009).

20. Rouault, T. A. The indispensable role of mammalian iron sulfur proteins in function and regulation of multiple diverse metabolic pathways. Biometals 32, 343-353 (2019)

21. Rouault, T. A. Biogenesis of iron-sulfur clusters in mammalian cells: new insights and relevance to human disease. Dis. Model Mech. 5, 155-164 (2012).

22. Braymer, J. J. \& Lill, R. Iron-sulfur cluster biogenesis and trafficking in mitochondria. J. Biol. Chem. 292, 12754-12763 (2017).

23. Kim, K. S., Maio, N., Singh, A. \& Rouault, T. A. Cytosolic HSC20 integrates de novo iron-sulfur cluster biogenesis with the CIAO1-mediated transfer to recipients. Hum. Mol. Genet. 27, 837-852 (2018).

24. Tong, W. H. \& Rouault, T. Distinct iron-sulfur cluster assembly complexes exist in the cytosol and mitochondria of human cells. EMBO J. 19, 5692-5700 (2000).

25. Tong, W. H. \& Rouault, T. A. Functions of mitochondrial ISCU and cytosolic ISCU in mammalian iron-sulfur cluster biogenesis and iron homeostasis. Cell Metab. 3, 199-210 (2006).

26. Lesuisse, E. et al. Iron use for haeme synthesis is under control of the yeast frataxin homologue (Yfh1). Hum. Mol. Genet. 12, 879-889 (2003).

27. Santos, R. et al. Candida albicans lacking the frataxin homologue: a relevant yeast model for studying the role of frataxin. Mol. Microbiol. 54, 507-519 (2004).

28. Maio, N. et al. Cochaperone binding to LYR motifs confers specificity of iron sulfur cluster delivery. Cell Metab. 19, 445-457 (2014).

29. Maio, N., Kim, K. S., Singh, A. \& Rouault, T. A. A single adaptable cochaperone-scaffold complex delivers nascent iron-sulfur clusters to mammalian respiratory chain complexes I-III. Cell Metab. 25, 945-953 e946 (2017).

30. Rouault, T. A. Iron-sulfur proteins hiding in plain sight. Nat. Chem. Biol. 11, 442-445 (2015).

31. Maio, N. et al. Disease-causing SDHAF1 mutations impair transfer of Fe-S clusters to SDHB. Cell Metab. 23, 292-302 (2016).

32. Tompa, P., Davey, N. E., Gibson, T. J. \& Babu, M. M. A million peptide motifs for the molecular biologist. Mol. Cell 55, 161-169 (2014).

33. Netz, D. J. et al. Eukaryotic DNA polymerases require an iron-sulfur cluster for the formation of active complexes. Nat. Chem. Biol. 8, 125-132 (2011)

34. Tong, W. H., Jameson, G. N., Huynh, B. H. \& Rouault, T. A. Subcellular compartmentalization of human Nfu, an iron-sulfur cluster scaffold protein, and its ability to assemble a [4Fe-4S] cluster. Proc. Natl Acad. Sci. USA 100, 9762-9767 (2003).

35. Duin, E. C. et al. [2Fe-2S] to [4Fe-4S] cluster conversion in Escherichia coli biotin synthase. Biochemistry 36, 11811-11820 (1997).

36. Arragain, $\mathrm{S}$. et al. Nonredox thiolation in tRNA occurring via sulfur activation by a [4Fe-4S] cluster. Proc. Natl Acad. Sci. USA 114, 7355-7360 (2017).

37. Lanz, N. D. et al. RlmN and AtsB as models for the overproduction and characterization of radical SAM proteins. Method Enzymol. 516, 125-152 (2012).

38. Johnson, D. C., Unciuleac, M. C. \& Dean, D. R. Controlled expression and functional analysis of iron-sulfur cluster biosynthetic components within Azotobacter vinelandii. J. Bacteriol. 188, 7551-7561 (2006).

39. Pandelia, M. E., Lanz, N. D., Booker, S. J. \& Krebs, C. Mossbauer spectroscopy of Fe/S proteins. Biochim. Biophys. Acta 1853, 1395-1405 (2015).

40. Flint, D. H. \& Allen, R. M. Iron-sulfur proteins with nonredox functions. Chem. Rev. 96, 2315-2334 (1996).

41. Beinert, H., Kennedy, M. C. \& Stout, C. D. Aconitase as iron-sulfur protein, enzyme, and iron-regulatory protein. Chem. Rev. 96, 2335-2374 (1996).

42. Emptage, M., Kent, T., Kennedy, M., Beinert, H. \& Munck, E. Mossbauer and Electron-Paramagnetic-Res studies of activated aconitase-development of a localized valence state at a subsite of the [4fe-4s] cluster on binding of citrate. Proc. Natl Acad. Sci. USA 80, 4674-4678 (1983).

43. Tschudy, D. P., Hess, R. A. \& Frykholm, B. C. Inhibition of deltaaminolevulinic acid dehydrase by 4,6-dioxoheptanoic acid. J. Biol. Chem. 256, 9915-9923 (1981).

44. Jaffe, E. K. The remarkable character of porphobilinogen synthase. Acc. Chem. Res. 49, 2509-2517 (2016).

45. Jaffe, E. K., Martins, J., Li, J., Kervinen, J. \& Dunbrack, R. L. The molecular mechanism of lead inhibition of human porphobilinogen synthase. J. Biol. Chem. 276, 1531-1537 (2001).

46. Mills-Davies, N. et al. Structural studies of substrate and product complexes of 5-aminolaevulinic acid dehydratase from humans, Escherichia coli and the hyperthermophile Pyrobaculum calidifontis. Acta Crystallogr. D. Biol. Crystallogr. 73, 9-21 (2017).

47. Rocha, J. B. T., Saraiva, R. A., Garcia, S. C., Gravina, F. S. \& Nogueira, C. W. Aminolevulinate dehydratase (delta-ALA-D) as marker protein of intoxication with metals and other pro-oxidant situations. Toxicol. Res. 1, 85-102 (2012).

48. Correia, M. A., Sinclair, P. R., De \& Matteis, F. Cytochrome P450 regulation: the interplay between its heme and apoprotein moieties in synthesis, assembly, repair, and disposal. Drug Metab. Rev. 43, 1-26 (2011). 
49. Sinclair, P. R., Gorman, N. \& Jacobs, J. M. Measurement of heme concentration. in Curr. Protoc. Toxicol. Chapter 8, Unit 8.3 (2001). https://currentprotocols. onlinelibrary.wiley.com/doi/full/10.1002/0471140856.tx0803s00?casa_token $=$ Un6YBh4lS1UAAAAA\%3A3ec8ybJjN-SPqg319M-GjnQ0-2qrXSicZK2fgMCL 4Y3fLC244brqqKAiXJwJSEnbVCVaqM8P0WbEVQ.

50. Vlasits, J. et al. Mechanisms of catalase activity of heme peroxidases. Arch. Biochem. Biophys. 500, 74-81 (2010).

51. Richards, M. P. \& Cousins, R. J. Mammalian zinc homeostasis: requirement for RNA and metallothionein synthesis. Biochem. Biophys. Res. Commun. 64, 1215-1223 (1975).

52. Davis, S. R. \& Cousins, R. J. Metallothionein expression in animals: a physiological perspective on function. J. Nutr. 130, 1085-1088 (2000).

53. Cheh, A. \& Neilands, J. B. Zinc, an essential metal-ion for beef liver deltaaminolevulinate dehydratase. Biochem. Biophys. Res. Commun. 55, 1060-1063 (1973).

54. Bevan, D. R., Bodlaender, P. \& Shemin, D. Mechanism of porphobilinogen synthase. Requirement of $\mathrm{Zn} 2+$ for enzyme activity. J. Biol. Chem. 255 2030-2035 (1980).

55. Shimberg, G. D. et al. Cleavage and polyadenylation specificity factor 30: An RNA-binding zinc-finger protein with an unexpected 2Fe-2S cluster. Proc. Natl Acad. Sci. USA 113, 4700-4705 (2016).

56. Conlan, A. R. et al. Crystal structure of Miner1: the redox-active 2Fe-2S protein causative in Wolfram Syndrome 2. J. Mol. Biol. 392, 143-153 (2009).

57. Jaffe, E. K. \& Hanes, D. Dissection of the early steps in the porphobilinogen synthase catalyzed reaction. Requirements for Schiff s base formation. J. Biol. Chem. 261, 9348-9353 (1986).

58. Jaffe, E. K. The porphobilinogen synthase catalyzed reaction mechanism. Bioorg. Chem. 32, 316-325 (2004).

59. Barnard, G. F., Itoh, R., Hohberger, L. H. \& Shemin, D. Mechanism of porphobilinogen synthase. Possible role of essential thiol groups. J. Biol. Chem. 252, 8965-8974 (1977)

60. Beinert, H., Kennedy, M. C. \& Stout, C. D. Aconitase as iron-sulfur protein, enzyme, and iron-regulatory protein. Chem. Rev. 96, 2335-2373 (1996).

61. Flint, D. H., Emptage, M. H., Finnegan, M. G., Fu, W. G. \& Johnson, M. K. The role and properties of the iron-sulfur cluster in Escherichia-Coli dihydroxy-acid dehydratase. J. Biol. Chem. 268, 14732-14742 (1993).

62. Esakova, O. A. et al. An unexpected species determined by X-ray crystallography that may represent an intermediate in the reaction catalyzed by quinolinate synthase. J. Am. Chem. Soc. 141, 14142-14151 (2019).

63. Saunders, A. H. et al. Characterization of quinolinate synthases from Escherichia coli, Mycobacterium tuberculosis, and Pyrococcus horikoshii indicates that $[4 \mathrm{Fe}-4 \mathrm{~S}]$ clusters are common cofactors throughout this class of enzymes. Biochemistry 47, 10999-11012 (2008).

64. Fuhring, J. et al. Octamerization is essential for enzymatic function of human UDP-glucose pyrophosphorylase. Glycobiology 23, 426-437 (2013).

65. Muh, U., Buckel, W. \& Bill, E. Mossbauer study of 4-hydroxybutyryl-CoA dehydratase-probing the role of an iron-sulfur cluster in an overall non-redox reaction. Eur. J. Biochem. 248, 380-384 (1997).

66. Martins, B. M., Dobbek, H., Cinkaya, I., Buckel, W. \& Messerschmidt, A. Crystal structure of 4-hydroxybutyryl-CoA dehydratase: radical catalysis involving a $[4 \mathrm{Fe}-4 \mathrm{~S}]$ cluster and flavin. Proc. Natl Acad. Sci. USA 101, 15645-15649 (2004).

67. Akagi, R., Yasui, Y., Harper, P. \& Sassa, S. A novel mutation of deltaaminolaevulinate dehydratase in a healthy child with $12 \%$ erythrocyte enzyme activity. Br. J. Haematol. 106, 931-937 (1999).

68. Breinig, S. et al. Control of tetrapyrrole biosynthesis by alternate quaternary forms of porphobilinogen synthase. Nat. Struct. Biol. 10, 757-763 (2003).

69. Rouault, T. A. Mammalian iron-sulphur proteins: novel insights into biogenesis and function. Nat. Rev. Mol. Cell Biol. 16, 45-55 (2015).

70. Erskine, P. T. et al. X-ray structure of 5-aminolaevulinate dehydratase, a hybrid aldolase. Nat. Struct. Biol. 4, 1025-1031 (1997).

71. Akagi, R. et al. delta-Aminolevulinate dehydratase (ALAD) porphyria: the first case in North America with two novel ALAD mutations. Mol. Genet. Metab. 87, 329-336 (2006).

72. Lawrence, S. H., Ramirez, U. D., Selwood, T., Stith, L. \& Jaffe, E. K. Allosteric inhibition of human porphobilinogen synthase. J. Biol. Chem. 284, 35807-35817 (2009).
73. Jaffe, E. K. \& Stith, L. ALAD porphyria is a conformational disease. Am. J. Hum. Genet. 80, 329-337 (2007).

74. Puy, H., Gouya, L. \& Deybach, J. C. Porphyrias. Lancet 375, 924-937 (2010).

75. Cappellini, M. D., Brancaleoni, V., Graziadei, G., Tavazzi, D. \& Di Pierro, E. Porphyrias at a glance: diagnosis and treatment. Intern. Emerg. Med. 5, S73-S80 (2010).

76. Phillips, J. D. Heme biosynthesis and the porphyrias. Mol. Genet. Metab. 128, 164-177 (2019).

77. Goncalves, T. L. et al. Oxidative stress and delta-ALA-D activity in different conditioning regimens in allogeneic bone marrow transplantation patients. Clin. Biochem. 42, 602-610 (2009).

78. Eschbach, J. W. The anemia of chronic renal failure: pathophysiology and the effects of recombinant erythropoietin. Kidney Int. 35, 134-148 (1989).

79. Fujita, H. Measurement of delta-aminolevulinate dehydratase activity. in Curr. Protoc. Toxicol. Chapter 8, Unit 8.6 (2001). https://currentprotocols. onlinelibrary.wiley.com/doi/full/10.1002/0471140856.tx0806s01.

\section{Acknowledgements}

We are grateful to all the members of our lab for constructive discussions and to Dr. Gregory Holmes-Hampton for his help on ICP-MS analysis. This work was supported by the Intramural Program of the Eunice Kennedy Shriver National Institute of Child Health and Human Development and the National Institutes of Health (GM-127079 to C.K.).

\section{Author contributions}

G.L. designed and performed the experiments, analyzed the data, and wrote the manuscript. D.S. performed the Mössbauer and EPR experiments, analyzed the data, and wrote the manuscript. N.M. designed and performed experiments and analyzed the data. W.T. analyzed the data. J.M.B. and C.K. analyzed the Mössbauer and EPR data. T.A.R. designed and supervised the study, analyzed the data, and wrote the manuscript. All authors revised the article critically.

\section{Competing interests}

The authors declare no competing interests.

\section{Additional information}

Supplementary information is available for this paper at https://doi.org/10.1038/s41467 020-20145-9.

Correspondence and requests for materials should be addressed to C.K. or T.A.R.

Peer review information Nature Communications thanks Koichiro Ishimori, Caryn Outten and the other, anonymous, reviewer for their contribution to the peer review of this work. Peer reviewer reports are available.

Reprints and permission information is available at http://www.nature.com/reprints

Publisher's note Springer Nature remains neutral with regard to jurisdictional claims in published maps and institutional affiliations.

Open Access This article is licensed under a Creative Commons Attribution 4.0 International License, which permits use, sharing, adaptation, distribution and reproduction in any medium or format, as long as you give appropriate credit to the original author(s) and the source, provide a link to the Creative Commons license, and indicate if changes were made. The images or other third party material in this article are included in the article's Creative Commons license, unless indicated otherwise in a credit line to the material. If material is not included in the article's Creative Commons license and your intended use is not permitted by statutory regulation or exceeds the permitted use, you will need to obtain permission directly from the copyright holder. To view a copy of this license, visit http://creativecommons.org/ licenses/by/4.0/.

(c) This is a U.S. Government work and not under copyright protection in the US; foreign copyright protection may apply 2020 